\title{
A Preliminary Study of the Effects of Nighttime Administration of the Serotonin Agonist, $m$-CPP, on Sleep Architecture and Behavior in Healthy Volunteers
}

\author{
Brian A. Lawlor, Paul A. Newhouse, Thomas J. Balkin, \\ Susan E. Molchan, Alan M. Mellow, Dennis L. Murphy, \\ and Trey Sunderland
}

The effects of m-chlorophenylpiperazine (m-CPP) $(0.5 \mathrm{mg} / \mathrm{kg})$ on sleep architecture and behavior were examined in six healthy volunteers following a single oral dose of the drug in a randomized, double-blind, placebo-controlled study. $\mathrm{m}$-CPP reduced total sleep time (TST) and sleep efficiency in all subjects. Slow-wave sleep (SWS) and rapid-eye-movement (REM) sleep were decreased and stage 1 sleep was prolonged in a majority of subjects. Prominent behavioral and psychological effects were reported in five out of six subjects following m-CPP (but not following placebo) that interfered with sleep. The sleep disruption and behavioral activation following nighttime administration of $\mathrm{m}-\mathrm{CPP}$ contrasts with the sedative properties of its parent compound, trazodone, suggesting that the hypnotic effect of trazodone is not related to the agonist profile of its metabolite, m-CPP.

\section{Introduction}

The recent development of selective agents for the serotonin (5-hydroxytryptamine [5HT]) system has reawakened interest in the potential usefulness of such agents to explore the contribution of the 5-HT system to human sleep mechanisms. For example, acute and chronic administration of the selective $5-\mathrm{HT}_{2}$ antagonist ritanserin increases slowwave sleep (SWS) in normal volunteers (Idzikowski et al i986, 1987), indicating that 5$\mathrm{HT}_{2}$ receptors may have an inhibitory effect on the control of human SWS. Single doses of the selective 5-HT reuptake inhibitors zimelidine and indalpine reduce the durativin of REM sleep and also decrease total sleep time (TST) (Nicholson and Pascoe 1986). Buspirone, a novel anxiolytic with $5-\mathrm{HT}_{1 \mathrm{~A}}$ agonist properties, reduces REM sleep in human insomniacs (Seidel et al 1985).

From the Division of Geriatric Psychiatry, Department of Psychiatry, Mount Sinai School of Medicine, New York, NY (BAL), the Neuroscience Research Unit, Department of Psychiatry, University of Vermont College of Medicine, Burington, VT (PAN), the Department of Behavioral Biology, Walter Reed Army Institute of Ressarch. Washington DC (TJB). the Laboratory of Clinical Science, National Institute of Mental Health, Bethesda, MD (SEM, DLM. TS), and the Department of Psychiatry, University of Michigan. Ann Arbor, Mil (AMM).

Address reprint requests to Brian A. Lawlor. MD, Department of Psychiatry, Box 1230. Mount Sinai School of Medicine, One Gustave L. Levy Place, New York, NY 10029.

Received July 28, 1989; revised August 6, 1990. 
Table 1. Effect of $m$-CPP and Placebon on Sleep Parameters in Normal Volunteers

\begin{tabular}{|c|c|c|c|c|c|c|c|c|}
\hline Subject & Sex & Age & Drug & TST & S1 & $\begin{array}{c}\% \\
\text { AST SI }\end{array}$ & S2 & $\begin{array}{c}\% \\
\text { AST S2 }\end{array}$ \\
\hline \multirow[t]{2}{*}{1} & $\mathbf{F}$ & 23 & $\mathbf{P}$ & 478 & 23.2 & 4.9 & 228.5 & 47.8 \\
\hline & & & D & 258 & 21.1 & 8.2 & 135.6 & 52.6 \\
\hline \multirow[t]{2}{*}{2} & $\mathbf{M}$ & 26 & $\mathbf{p}$ & 374 & 64.9 & 17.3 & 235.0 & 62.8 \\
\hline & & & D & 261 & 23.2 & 8.9 & 204.1 & 78.0 \\
\hline \multirow[t]{2}{*}{3} & $\mathbf{M}$ & 31 & $\mathbf{P}$ & 350 & 16.6 & 4.7 & 179.7 & 51.4 \\
\hline & & & D & 215 & 125.9 & 58.4 & 61.1 & 28.3 \\
\hline \multirow[t]{2}{*}{4} & $\mathbf{M}$ & 76 & $\mathbf{P}$ & 345 & 60.5 & 17.5 & 214.8 & 62.2 \\
\hline & & & D & 232 & 86.8 & 37.3 & 98.2 & 42.2 \\
\hline \multirow[t]{2}{*}{5} & $\mathbf{M}$ & 66 & $\mathbf{P}$ & 324 & 33.7 & 10.4 & 203.5 & 62.8 \\
\hline & & & D & 98 & 14.6 & 14.8 & 70.7 & 71.9 \\
\hline \multirow[t]{2}{*}{6} & $\mathbf{M}$ & 26 & $\mathbf{P}$ & 420 & 29.9 & 7.1 & 246.9 & 58.8 \\
\hline & & & D & 396 & 41.9 & 10.6 & 220.7 & 55.7 \\
\hline
\end{tabular}

TST = total sleep time; AST = actual sleep time; $S 1=$ stage $1:$ S2 = stage $2 ;$ SWS = slow-wave jleep; REM = rapid eye movement; REM latency is calculated from time of sleep onset (min) as defined by stage 2 until the time of first REM periud; sleep latency is defined as time $(\mathrm{min})$ until onset of stage 2 sleep. $\mathrm{P}=$ placebo; $\mathrm{D}=m \cdot \mathrm{CPP}$

"This was a very long ( $>4 \mathrm{hr}$ ) wake period.

Meta-chlorophenylpiperazine ( $m$-CPP), a metabolite of the antidepressant trazodone, demonstrates selective 5-HT agonist properties in animals (Rokosz-Pelc et al 1980) and is currently being studied as a probe of central serotonergic neuronal systems in humans (Mueiler et al 1985; Murphy et al 1989; Lawlor et al 1989). Although $m$-CPP appears to have relative selectivity for the 5-HT $1 \mathrm{~B}$ receptor subtype in rodents (Sills et al 1984), the fact that $m-C P P$ binds potently to $5-\mathrm{HT}_{1 \mathrm{~A}}, 5-\mathrm{HT}_{1 \mathrm{D}}$, and $5-\mathrm{HT}_{2}$ receptors in human brain (Hamik and Peroutka 1989), together with the failure to demonstrate the existence of 5-HT $\mathrm{T}_{1 \mathrm{~B}}$ receptors in human brain (Hoyer et al 1986; Heuring et al 1986), raises questions about the exact 5-HT receptor site of action of this compound in humans. More recent studies suggest that $m$-CPP may have agonist activity at $5-\mathrm{HT}_{1 \mathrm{C}}$ receptors in animals (Kennett and Curzon 1988).

In rodents, $m$-CPP reduces locomotor activity (Aulakh et al 1987; Kennett and Curzon 1988), and in nonhuman primates, intravenous (IV) $m$-CPP produces marked sedation (Aloi et al 1984). It has been suggested that the known sedative properties of trazodone, the parent compound, may involve its metabolism to $m$-CPP (Kennett and Curzon 1988). Previous studies in human using acute IV administration of $m$-CPP have produced somewhat conflicting results, with self-reports of significantly increased drowsiness in some studies (Charney et al 1987; Lawlor et al 1989) but not others (Murphy et al 1989). Acute oral administration of $m$-CPP, however, does not significantly increase drowsiness or sleepiness following daytime administration (Mueller et al 1985; Murphy et al 1989).

In this preliminary study, the effects of orally administered $m$-CPP $(0.5 \mathrm{mg} / \mathrm{kg})$ on sleep architecture and behavior in six healthy volunteers were examined.

\section{Methods}

Six subjects (five male, one female; range 24-76 years) were included in the study. Because of the preliminary nature of this investigation, subjects in a wide age range were included. All subjects were in good physical health as determined by normal physical examination and blood chemistries, and were drug free for at least 3 weeks prior to the 
Table 1. (Continued)

\begin{tabular}{ccccccccc}
\hline SWS & $\begin{array}{c}\text { \% AST } \\
\text { SWS }\end{array}$ & REM & $\begin{array}{c}\text { \% AST } \\
\text { REM }\end{array}$ & $\begin{array}{c}\text { REM } \\
\text { periods }\end{array}$ & $\begin{array}{c}\text { Awakenings } \\
>120 \text { Sec }\end{array}$ & $\begin{array}{c}\text { Sleep } \\
\text { latency }\end{array}$ & $\begin{array}{c}\text { REM } \\
\text { latency }\end{array}$ & $\begin{array}{c}\text { Sleep } \\
\text { efficiency \% }\end{array}$ \\
\hline 86.8 & 18.1 & 139.8 & 29.2 & 14 & 0 & 13.9 & 98.9 & 95 \\
66.6 & 25.8 & 34.6 & 13.4 & 3 & $1^{*}$ & 15.3 & 416.0 & 46 \\
11.5 & 3.1 & 62.9 & 16.8 & 5 & 9 & 17.7 & 62.9 & 85 \\
0 & 0 & 34.2 & 13.1 & 5 & 2 & 263.4 & 6.2 & 48 \\
47.7 & 13.6 & 105.7 & 30.2 & 12 & 0 & 5.3 & 63.4 & 96 \\
5.9 & 2.7 & 22.7 & 10.5 & 3 & 3 & 60.8 & 255.2 & 62 \\
0 & 0 & 70.1 & 20.3 & 9 & 21 & 19.7 & 69.7 & 59 \\
0 & 0 & 47.5 & 20.4 & 5 & 24 & 37.2 & 170.5 & 39 \\
6.5 & 2.0 & 80.3 & 24.8 & 19 & 12 & 60.3 & 76.5 & 70 \\
0 & 0 & 13.1 & 13.3 & 1 & 10 & 305.4 & 2.7 & 36 \\
54.2 & 12.9 & 88.8 & 21.2 & 6 & 0 & 8.0 & 149.3 & 96 \\
0 & 0 & 133.3 & 33.7 & 15 & 6 & 9.6 & 3.5 & 90 \\
\hline
\end{tabular}

study. Subjects were screened to exclude those with any personal or family history of psychiatric illness, sleep disorders, or substance abuse.

After one night of habituation to sleeping conditions and recording, subjects underwent drug or placebo treatment on two subsequent study nights separated by at least $72 \mathrm{hr}$. Subjects fasted from 2:00 PM on the days they received either oral $m$-CPP $(0.5 \mathrm{mg} / \mathrm{kg})$ or placebo. The $0.5-\mathrm{mg} / \mathrm{kg}$ dose was chosen because it produced physiological and neuroendocrine effects consistent with 5-HT stimulation in earlier studies (Mueller et al $1985,1986)$. Subjects were fasted because nausea had been previously reported in some subjects following oral $m$-CPP administration (Mueller et al 1985). Electroencephalogram (EEG), electromyogram (EMG), and electrooculogram (EOG) electrodes were placed in a standard configuration and connected to an Oxford Medilog 24-hr ambulatory EEG recorder at 7:30 PM; subjects then received either $m$-CPP or placebo at 10:00 PM under double-blind conditions. They were instructed to press an event marker on the recorder when they retired and to press it again when they got out of bed the following morning. After receiving the "blind" capsules, they were permitted to retire to bed. Electrodes were removed from subjects at 8:00 AM the following morning. All subjects were questioned about their subjective experience on the mornings following both drug and placebe treatments, and were asked to describe their experiences following both treatment conditions.

The EEG, EOG, and EMG data were scored blind to drug condition on a display scieen in 16-sec epochs by two scorers (PAN and TJB) according to the criteria established by Rechtschaffen and Kales (1968). For the purpose of scoring, stages III and IV were combined as SWS.

\section{Results}

\section{Effects on Sleep Parameters}

The sleep scores for each subject following $m$-CPP and placebo are shown in Table 1. $m$-CPP reduced TST and sleep efficiency in all subjects. When the individual data were expressed as number of minutes for each sleep stage, $m$-CPP decreased SWS in all subjects and reduced REM in five of six subjects compared to placebo. When percentages of 
actual sleep time (\% AST) were examined, five of six subjects showed an increase in the $\%$ AST for stage 1, and four of six subjects showed decreases in \% AST for SWS and REM following $m$-CPP compared to placebo.

\section{Behavioral Effects}

Five of the six subjects reported difficulty in falling asleep on the evening of $m$-CPP administration. Three subjects reported feeling stimulated, unable to relax, and having racing thoughts. One subject reported that his "mind jumped from subject to subject, dealing with philosophical issues and creationism." Another subject reported feelings of paranoia and fear, although without any logical reason. The one female subject participating in the study became nauseous and vomited twice about 45 min following $m$-CPP administration; nausea and vomiting were preceded and followed by overwhelming feelings of loneliness and sadness accompanied by crying spells that lasted about $60 \mathrm{~min}$. Fialf of the subjects reported a chilled sensation and mild perceptual changes such as the feeling that the room was spinning, beginning about 45-60 min after administration of $m$-CPP. These same five subjects felt that their sleep had been disrupted following $m$ CPP, and felt more fatigued the next morning. Of the six subjects, only the elderly male subject (who showed no SWS on either drug or placebo nights) reported no subjective changes or side effects following $m-C P P$ treatm int. None $c^{r}$ the subjects reported any bchavioral or somatic effects after placebo treatmen.

\section{Discussion}

This is the first report of the effects of nighttime administration of $m$-CPP on sleep architecture and behavior in humans. Although the small number and wide age range of subjects in this study limits the interpretation of the findings, the individual sleep data and behavioral reports remain of interest. $m$-CPP produced consistent decreases in TST and sleep efficiency in all subjects, with increases in stage 1 (\% AST), and decreases in REM and SWS (when expressed as \% AST) in a majority of subjects. A reduction in REM and SWS appears to be characteristic of a 5-HT agonist profile in animals (Dugovic and Wauquier 1987; Fornal and Radulovacki 1983), suggesting that the effects of $m$-CPP on sleep architecture in this study could reflect its 5-HT agonist activity.

Trazodone, the parent compound of $m$-CPP, has mixed effects on 5-HT transmission, including weak 5-HT reuptake inhibition, 5-HT antagonism, and direct 5-HT agonist effects that may be related to the formation of its metabolite, $m$-CPP (Maj et al 1979). Trazodone is the only well-studied thymoleptic agent, with the exception of lithium (Kupfer et al 1974; Fristal et al 1989), that increases SWS (Montgomery et al 1983). When trazodone is administered acutely, it produces sedative effects of therapeutic benefit to depressed patients (Mouret et al 1988) and increases SWS soen after initial administration in volunteer poor sleepers (Montgomery et al 1983). Considering the disruptive effect of $m$-CPP on sleep and the activating effects of this compound follc ving nighttime administration in this study, it would appear that the sedative and SWS-ennancing effects of trazodone are unlikely $\mathrm{J}$ be explained by the action of its metabolite, $m$-CPP.

Another interesting aspect of this study was the prominent behavioral and psychological effects reported by subjects following oral $m$-CPP. Previous experience with acute oral daytime administration of this dose of $m$-CPP has shown only modest behavioral effects in healthy normal volunteers (Mueller et al 1985; Murphy et al 1989). The experimental 
situation and the context in which a drug is administered can affect how the subject responds; decreased environmental structure at nighttime could account for the increased subjective reports following $m$-CPP in this study. Circadian variation in 5-HT function may also play a role, with possibly greater responsivity to acute 5-HT stimulation because of increased serotonergic function at night (Kovacevic and Radulovacki 1976).

In conclusion, nighttime administration of $m$-CPP produced reductions in TST and sleep efficiency in all subjects and was accompanied by prominent subjective behavioral reports. The disruption in sleep and behavioral activation following nighttime administration of $m$-CPP contrasts with the sedative properties of trazodone, $m$-CPP's parent compound, suggesting that $m$-CPP is probably not responsible for the sleep-enhancing properties of trazodone.

\section{References}

Aloi JA, Insel TR, Mueller EA, Murphy DL (1984): Neuroendocrine and behavioral effects of $m$ chlorophenylpiperazine administration in thesus monkeys. Life Sci 34:1325-1331.

Aulakh CS, Cohen RM, Hill JL, Murphy DL, Zohar J (1987): Long-term imipramine treatment enhances locomotor and food intake suppressant effects of $m$-chlorophenylpiperazine in rats. Br J Pharmacol 91:747-752.

Charney DS, Woods SW, Goodman WK, Heninger GR (1987): Serotonin function in anxiety. II. Effects of the serotonin agonist $m$-CPP in panic disorder patients and heaithy subjects. $\vec{P} s y$ chopharmacology 92:14-24.

Dugovic C, Wauquier A (1987): 5-HT 2 receptors could be primarily involved in the regulation of siow-wave sleep in the rat. Eur $J$ Pharmacol 137:145-146.

Fornal C, Radulovacki M (1983): Sleep suppressant action of fenfluramine in rats. I. Relation to postsynaptic serotonergic stimulation. J Pharmacol Exp Ther 225:667-674.

Fristal KJ, Sharpley AL, Solomon RA, Cowen PJ (1989): Lithium increases slow wave sleep: Possible mediation by brain 5-HT, receptors? Psychopharmacology 98:139-140.

Hamik A, Peroutka SJ (1989): 1-( $m$-Chlorophenyl)piperazine ( $m$-CPP) interactions with neurotransmitter receptors in the human brain. Biol Psychiatry 25:569-575.

Heuring RE, Schegel JR, Peroutka SJ (1986): Species variations in RU 24969 interactions with non-5-HT1A binding sites. Eur J Pharmacol 122:279-282.

Hoyer D, Pazos A, Probst A, Palacios JM (1986): Serotonin receptors in the human brain. I. Characterization and autoradiographic localization of 5-HT1A recognition sites. Apparent absence of 5-HT1B sites. Brain Res 376:85-96.

Idzikowski C, Mills FJ, Glennard R (1986): 5-Hydroxytryptamine-2-antagonist increases human slow wave sleep. Brain Res 378:164-168.

Idzikowski C, Cowen PJ, Nutt D, Mills FJ (1987): The effects of chronic ritanserin treatment on sleep and the neuroendocrine response to L-tryptophan. Psychopharmacology 93:416-420.

Kennett GA, Curzon G (1988): Evidence that $\mathrm{m}$-CPP may have behavioral effects mediated by central 5-HT1C receptors. Br J Pharmacol 94:137-147.

Kovacevic R, Radulovacki M (1976): Monoamine changes in the brain of cats during slow wave sleep. Science 193:1025-1027.

Kupfrr DJ, Reynolds CF, Weiss BL, Foster FG (1974): Lithium Carbonate and sleep in affective diso:ders: Further consideraticns. Arch Gen Psychiniry 30:79-84.

Lawlor BA, Sunderland T, Mellow AM, Hill JL, Molchan SE, Murphy DL (1989): Hyperresponsivity to the serotonin agonist, $m$-chiorophenylpiperazine, in Alzheimer's disease: A controlled study. A rh Gen Psychiatry 46:542-549.

Maj J, Palider W, Rawlow A (1979): Trazodone, a central antagonist and agonist. $J$ Neural Transm 44:237-248. 
Montgomery I, Oswald I, Morgan K, Adam K (1983): Trazodone enhances sleep in subjective quality but not in objective duration. Br J Clin Pharmacol 16:139-144.

Mouret J, Lemoine P, Minuit MP, Benkelfat C, Renardet M (1988): Effects of trazodone on the sleep of depressed subjects: A polygraphic study. Psychopharmacology 95:S37-S43.

Mueller EA, Murphy DL, Sunderland T (1985): Neuroendocrine effects of $m$-chlorophenylpiperazine, a serotonin agonist, in humans. J Clin Endocrinol Metab 61:1179-1184.

Mueller EA, Murphy DL, Sunderland T (1986): Further studies of the putative serotonin agonist, $m$-chlorophenylpiperazine: Evidence for a serotonin receptor mediated mechanism of action in humans. Psychopharmacology 89:388-391.

Murphy DL, Mueller EA, Hill JL, Tolliver TJ, Jacobsen FM (1989): Comparative anxiogenic, neuroendocrine, and other physiologic effects of $m$-chlorophenylpiperazine given intravenously or orally to healthy volunteers. Psychopharmacology 98:275-282.

Nicholson AN, Pascoe PA (1986): 5-Hydroxytryptamine and noradrenaline uptake inhibition: Studies on slesp in man. Neuropharmacology 25:1079-1083.

Rechtschaffen A. Kales A (1968): A Manual of Standardized Terminology, Techniques and Scoring System for Sleep of Human Subjects. Bethesda, MD: NIMH.

Rokos7.Pelc A, Antikiewicz-Michaluk L, Vetulani J (1980): 5-Hydroxytryptamine-like properties of $m$-chlorophenylpiperazine: Comparison with quipazine. J Pharm Pharmacol 32:220-222.

Seidel WF, Cohen SA. Sliwise NG, Dement WC (1985): Buspirone, an anxiolytic without sedative properties. Psychopharmacology 87:371-373.

Sills MA, Wolfe BB, Frazer A (1984): Determination of selective and nonselective compounds for the 5-HT1A and 5-HT1B receptor subtypes in rat frontal cortex. J Pharmacol Exp Ther 231:480-487. 